\title{
Effect of treatment with depot somatostatin analogue octreotide on primary hyperparathyroidism (PHP) in multiple endocrine neoplasia type 1 (MEN1) patients
}

\author{
Antongiulio Faggiano*, Lidice Brandao Tavares*, Libuse Tauchmanova*, Francesco Milone*, Gelsomina \\ Mansueto†, Valeria Ramundo*, Maria Laura Del Basso De Caro†, Gaetano Lombardi*, Gaetano De Rosa \\ and Annamaria Colao* \\ Departments of ${ }^{\star}$ Molecular and Clinical Endocrinology and Oncology and $\dagger$ Biomorphological and Functional Sciences 'Federico \\ II' University of Naples, Italy
}

\section{Summary}

Background In patients with multiple endocrine neoplasia type 1 (MEN1), expression of somatostatin receptor (SST) in parathyroid adenomas and effectiveness of therapy with somatostatin analogues on primary hyperparathyroidism (PHP) have been scarcely investigated. Objective To evaluate the effects of depot long acting octreotide (OCT-LAR) in patients with MEN1-related PHP.

Patients Eight patients with a genetically confirmed MEN1, presenting both PHP and duodeno-pancreatic neuroendocrine tumours (NET), were enrolled.

Design The initial treatment was OCT-LAR $30 \mathrm{mg}$ every 4 weeks. This therapy was established to stabilize the duodeno-pancreatic NET before to perform parathyroidectomy for PHP. Before OCT-LAR therapy, a SST scintigraphy was performed in all patients. SST subtype 2A immunohistochemistry was performed on parathyroid tumour samples from three patients undergone parathyroidectomy after OCT-LAR therapy.

Measurements Serum concentrations of PTH, calcium and phosphorus as well as the 24 -h urine calcium : creatinine ratio and the renal threshold phosphate concentration were evaluated before and after OCT-LAR.

Results After OCT-LAR therapy, hypercalcaemia and hypercalciuria normalized in $75 \%$ and $62.5 \%$ of patients, respectively, and serum phosphorus and renal threshold phosphate significantly increased. Serum PTH concentrations significantly decreased in all patients and normalized in two of them. SST subtype 2A immunostaining was found in all parathyroid adenomas investigated, while SST scintigraphy showed a positive parathyroid tumour uptake in three of eight patients $(37 \cdot 5 \%)$.

Conclusion Six months of OCT-LAR therapy controlled hypercalcaemia and hypercalciuria in two-thirds of patients with

Correspondence: Antongiulio Faggiano, Department of Molecular and Clinical Endocrinology and Oncology, 'Federico II' University, Naples Via Sergio Pansini 5, 80131, Naples, Italy. Tel.: +39 081 7464285;

Fax: +39 081 5465443; E-mail: afaggian@unina.it
MEN1-related PHP. Direct OCT-LAR effects mediated by binding to SST expression on parathyroid tumour cells are likely the main mechanism to explain the activity of this compound on calcium and phosphorus abnormalities in MEN1 PHP.

(Received 4 March 2008; returned for revision 7 April 2008; finally revised 11 April 2008; accepted 3 May 2008)

\section{Introduction}

Multiple endocrine neoplasia type 1 (MEN1) is characterized by a variable phenotypic expressiveness; primary hyperparathyroidism (PHP), however, occurs in $90-100 \%$ of patients and is the MEN1 earliest manifestation in $90 \%$ of the cases. ${ }^{1-3}$ A latent PHP occurs in the vast majority of patients, even when a duodeno-pancreatic neuroendocrine tumour (NET) or a pituitary adenoma are the first MEN1 clinical manifestations.

Nowadays, no effective medical therapy for PHP is available, although preliminary studies reported cinacalcet, a calcimimetic compound, to be effective in normalizing hypercalcaemia in patients with sporadic PHP. ${ }^{4,5}$ Somatostatin analogues (SSA) are compounds known to control hormone excess and to stabilize tumour growth in several type of NET. ${ }^{6,7}$ In patients with MEN1 they are used to target duodeno-pancreatic NET and/or pituitary adenomas. ${ }^{8,9}$

Few and discordant data have been reported on the effects of SSA in PHP. Preliminary clinical experience with subcutaneous octreotide $200 \mu \mathrm{g}$ daily reportedly improved hypercalciuria but was ineffective on hypercalcaemia and PTH levels. ${ }^{10,11}$ Similarly, no effect was observed after an acute test with octreotide in 40 patients with PHP. ${ }^{12}$ More recently, one of two patients with MEN1-related PHP had decreased PTH levels during a 6-month treatment with subcutaneous octreotide. $^{13}$

It has been demonstrated in other NET models that depot octreotide (OCT-LAR) is much more effective than its short-acting formulation in controlling hormone excess. ${ }^{14}$

The present study was designed to investigate whether therapy with OCT-LAR might improve PHP in patients with MEN1. 


\section{Patients and methods}

\section{Patients}

Among 18 patients with MEN1-related PHP who were admitted to the Department of Endocrinology of the 'Federico II' University of Naples from 1 January 2004 to 31 March 2007, eight patients with both PHP and duodeno-pancreatic NET were included in the study. These patients (four males, four females) had a mean age of $41 \cdot 6 \pm 5 \cdot 0$ years (range: $19-66$ ). All were positive to the MEN1 gene mutation analysis. At diagnosis, MEN1 clinical features included PHP with multiparathyroid gland involvement, and one or more NET in the duodeno-pancreatic tract. NET were stable in five patients and progressive in three. One patient had liver metastases. Chromogranin-A and gastrin excess were detected in all and five patients, respectively. Therefore, all patients were susceptible to be treated with OCT-LAR for the duodeno-pancreatic NET and, at the same time, all of them were studied for the effects of OCT-LAR on PHP which also affected these patients. All patients had normal renal function as expressed by creatinine clearance.

OCT-LAR therapy was given at a dose of $30 \mathrm{mg}$ i.m. every 4 weeks. Parathyroid surgery was planned when NET were stabilized. Thus, in all of the patients we evaluated the effects of OCT-LAR on PHP by measuring serum PTH, calcium and phosphorus levels and urinary excretion of calcium and phosphorus before and 3 and 6 months after the beginning of the OCT-LAR treatment. All patients were advised to increase water intake to at least 3 litres a day.

\section{Biochemical evaluation}

Blood samples were collected for measurement of serum calcium, phosphorus and $\mathrm{PTH}$ at baseline and at each study visit after an overnight fast. Urine samples were collected over $24 \mathrm{~h}$ and after an overnight fast at baseline and at each visit for the measurement of calcium and phosphorus excretion; 24-h urine calcium excretion was factored by creatinine excretion. To evaluate renal tubular re-absorption of phosphate, the renal threshold for phosphate (maximal transport of phosphate/GFR, normal $0.75-1.37 \mathrm{mmol} / \mathrm{l}$ glomerular filtrate; $2 \cdot 3-4 \cdot 2 \mathrm{mg} / \mathrm{l}$ glomerular filtrate) was determined at baseline and at each study visit by using the normogram by Walton and Bijvoet. $^{15}$

\section{Somatostatin receptor scintigraphy}

In vivo evaluation of somatostatin receptor (SST) expression was performed in all patients at the time of diagnosis by using radioreceptor whole-body scan with $\left[{ }^{111}\right.$ In-DTPA-D-Phe ${ }^{1}$ octreotide, as previously described. ${ }^{16}$

\section{Immunohistochemistry}

After 6 months of OCT-LAR therapy, three out of the eight patients underwent parathyroidectomy. In these patients, SST subtype $2 \mathrm{~A}$ (SST2A) expression was evaluated on parathyroid tumour samples by using immunohistochemistry. Immunohistochemical staining was performed on $4 \mu \mathrm{m}$ thick serial sections of each adenoma mounted on pretreated slides with poly L-Lysine. Sections were pretreated with a heat-induced antigen retrieval technique, with incubation in a $650 \mathrm{~W}$ microwave oven (three sequential step a 10 min each in citrate buffer ( $\mathrm{pH} 6 \cdot 0) 10 \mathrm{~mm}$ ), for antigen unmasking and then incubated for $20 \mathrm{~min}$ at room temperature with $0 \cdot 3 \%$ hydrogen peroxide in methanol, to quench the endogenous peroxidases. After successive washings in PBS (saline phosphate tampon) (Bio-Optica M107, Milan Italy) for $20 \mathrm{~min}$. Further incubation with nonimmune mouse serum (1:20, Dakopatts, Hamburg, Germany) diluted in PBS-bovine serum albumin (1\%) for $25 \mathrm{~min}$ was performed to prevent nonspecific immunostaining. After washing three times in PBS, immunostaining was performed by using the anti-SST2A (BioTrend, Cologne, Germany, code SS-800) as primary antibody. Incubation was carried at $37^{\circ} \mathrm{C}$ overnight. After incubation and three washing cycles in PBS, sections were incubated with biotinyled link antibodies and peroxidase-labelled streptavidine (LSAB-HRP, Dako, Italy). 3,3 Diaminobenzidine (DAB, Vector Laboratories, Burlingame, $\mathrm{CA}$ ) with $0 \cdot 3 \% \mathrm{H}_{2} \mathrm{O}_{2}$ was used as substrate chromogen solution. After nuclear counterstaining with Mayer's haematoxylin, sections were mounted with synthetic medium (Entellan, Dermstad, Germany). Sections of pancreatic islets and breast cancer were used as positive controls. The negative controls were obtained by using mouse or rabbit serum with no specific reactivity. A semiquantitative scoring system was used, as previously described. ${ }^{17}$ The subcellular localization and the extent of the staining were both considered as follows: score 0 : absence of immunoreactivity; score 1: cytoplasm immunoreactivity only, either focal or diffuse; score 2 : membranous reactivity in $<50 \%$ of tumour cells, irrespective of the presence of cytoplasm staining; score 3: circumferential membranous reactivity in $>50 \%$ of tumour cells, irrespective of the presence of cytoplasm staining. The immunohistochemical findings were analysed by two pathologists (MLDBDC; GM) independently. There was a complete agreement in the interpretation of the immunoreactivity between the two pathologists.

\section{Statistical analysis}

The statistical analysis was performed by spss for Windows version 10 (SPSS Inc., Chicago, IL). Data are reported as mean \pm SEM. The significance was set at $5 \%$. The comparison between the numerical data was performed by Student's $t$-test. The comparison between the categorical data was performed by $\chi^{2}$-test with Yates correction, Fisher exact test as appropriate. The correlation study was performed by the linear regression analysis calculating the Pearson's coefficient.

\section{Results}

At diagnosis, all patients had hypercalcaemia, hypercalciuria, hypophosphataemia, high serum PTH and evidence of enlargement of at least one parathyroid at the colour-Doppler neck ultrasonography and parathyroid scintigraphy. In three patients (37.5\%), SST scintigraphy showed positive parathyroid tumour uptake (Table 1). At immunohistochemistry, SST2A was positive in all parathyroid adenomas evaluated: score 3 in one (patient number 7, Table 1) and 
Table 1. Clinical, biochemical and morpho-functional profile in 8 patients with MEN1-dependent primary hyperparathyroidism

\begin{tabular}{|c|c|c|c|c|c|c|}
\hline Age/gender & $\begin{array}{l}\text { Somatostatin } \\
\text { receptor scintigraphy }\end{array}$ & $\begin{array}{l}\text { Serum PTH pmol/1 } \\
\text { (normal, } 1-7 \cdot 5 \text { ) }\end{array}$ & $\begin{array}{l}\text { Serum calcium mmol/1 } \\
\text { (normal, } 2 \cdot 20-2 \cdot 58)\end{array}$ & $\begin{array}{l}\text { Serum phosphorus } \\
\mathrm{mmol} / 1(0 \cdot 80-1 \cdot 60)\end{array}$ & $\begin{array}{l}\text { 24-h urine calcium : } \\
\text { creatinine mg ratio }\end{array}$ & $\begin{array}{l}\text { Renal phosphate } \\
\text { threshold mmol/l GF }\end{array}$ \\
\hline 1. $45 / \mathrm{M}$ & Negative & $10 \cdot 8$ & $2 \cdot 74$ & 0.74 & $0 \cdot 63$ & $0 \cdot 38$ \\
\hline 2. $42 / \mathrm{F}$ & Negative & $9 \cdot 5$ & $2 \cdot 55$ & $0 \cdot 81$ & $0 \cdot 61$ & $0 \cdot 75$ \\
\hline 3. $35 / \mathrm{M}$ & Negative & $13 \cdot 3$ & 2.79 & $0 \cdot 87$ & $0 \cdot 45$ & $0 \cdot 52$ \\
\hline 4. $32 / \mathrm{F}$ & Negative & $9 \cdot 2$ & 2.79 & $0 \cdot 84$ & $0 \cdot 91$ & $0 \cdot 70$ \\
\hline 5. $66 / \mathrm{M}$ & Positive & $10 \cdot 2$ & $3 \cdot 01$ & $0 \cdot 90$ & $0 \cdot 55$ & $0 \cdot 73$ \\
\hline 6. 19/F & Negative & $7 \cdot 6$ & $2 \cdot 77$ & $0 \cdot 84$ & $0 \cdot 57$ & $0 \cdot 75$ \\
\hline 7. $41 / \mathrm{M}$ & Positive & $8 \cdot 8$ & $2 \cdot 74$ & 0.94 & $0 \cdot 35$ & $0 \cdot 80$ \\
\hline $8.53 / \mathrm{F}$ & Positive & $31 \cdot 2$ & $2 \cdot 79$ & $0 \cdot 84$ & $0 \cdot 58$ & $0 \cdot 60$ \\
\hline
\end{tabular}

score 2 in two cases (patient numbers 3 and 6, Table 1) (Fig. 1). SST2A immunoreactivity was specific as revealed by negative control experiments. SST scintigraphy was positive in the patient with score 3 SST2A immunostaining and negative in those with score 2 SST2A immunostaining.

Before OCT-LAR therapy, serum PTH, calcium and phosphorus concentrations did not significantly change during a 3 month follow-up period (Figs 2 and 3).

After the introduction of OCT-LAR therapy, serum calcium progressively decreased in all patients (Fig. 3). After 3 months of therapy, serum calcium was significantly decreased while phosphorus was significantly increased when compared to baseline. No significant change occurred in serum PTH within 3 months (Fig. 2). After 6 months of therapy, no further variation was observed in serum calcium and phosphorus as compared to 3 month follow-up. Serum PTH concentrations were significantly decreased when compared to baseline (Fig. 2).

The 24-h urine calcium : creatinine ratio and the renal threshold phosphate concentration were unchanged during the 3-month observation before OCT-LAR administration. During OCT-LAR therapy, the urine calcium : creatinine ratio progressively decreased in all patients (Fig. 3). Three months after OCT-LAR treatment, the calcium : creatinine ratio significantly decreased. After 6 months, a further significant decrease occurred (Fig. 2). The renal threshold phosphate concentration significantly increased as compared to baseline, 3 months after OCT-LAR therapy; a further but not significant increase was observed at 6 month evaluation (Fig. 2).

At the end of the 6 month follow-up, serum and urinary calcium levels were within the normal range in $6(75 \%)$ and $5(62 \cdot 5 \%)$ of 8 patients, respectively, while PTH plasma levels normalized in 2 of 8 patients $(25 \%)$.

\section{Discussion}

PHP is the most common endocrine disorder associated with MEN1 syndrome. ${ }^{1-3}$ The only curative therapy is surgery, which is required to remove all hyperfunctioning parathyroid tissue. Since MEN1-related PHP affects all the parathyroid tissue, resulting in multiple parathyroid adenomas or diffuse hyperplasia, surgical treatment for MEN1 patients should be a near-total or total parathyroidectomy. ${ }^{18,19}$ After curative surgery, hypoparathyroidism may occur and hyperparathyroidism may relapse later as well, resulting in decreased quality of life and difficult control of calcium homeostasis. $^{19,20}$
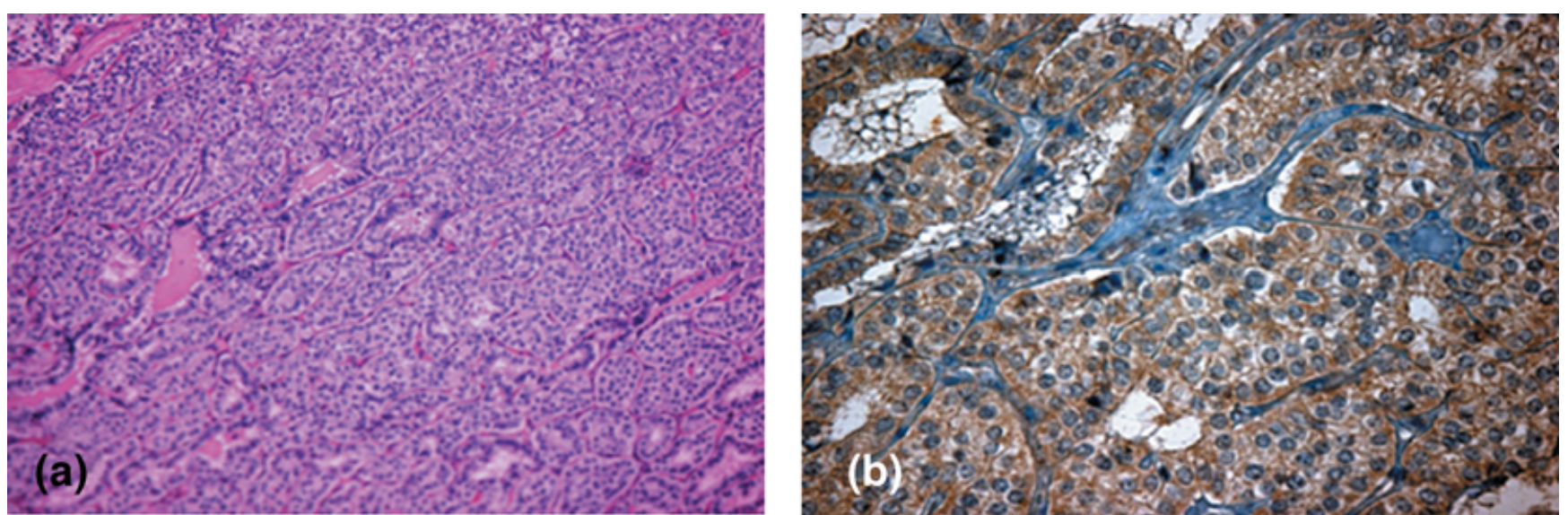

Fig. 1 (a) Photomicrographs: H\&E staining showing hypercellular, homogeneus, well-vascularized and sepimented tumour tissue (Magnification $\times 100$ ). (b) Somatostatin receptor subtype $2 \mathrm{~A}$ immunostaining showing diffuse cytoplasmic pattern with cell membrane expression in more than $50 \%$ of tumour cells (Magnification $\times 400)$. 

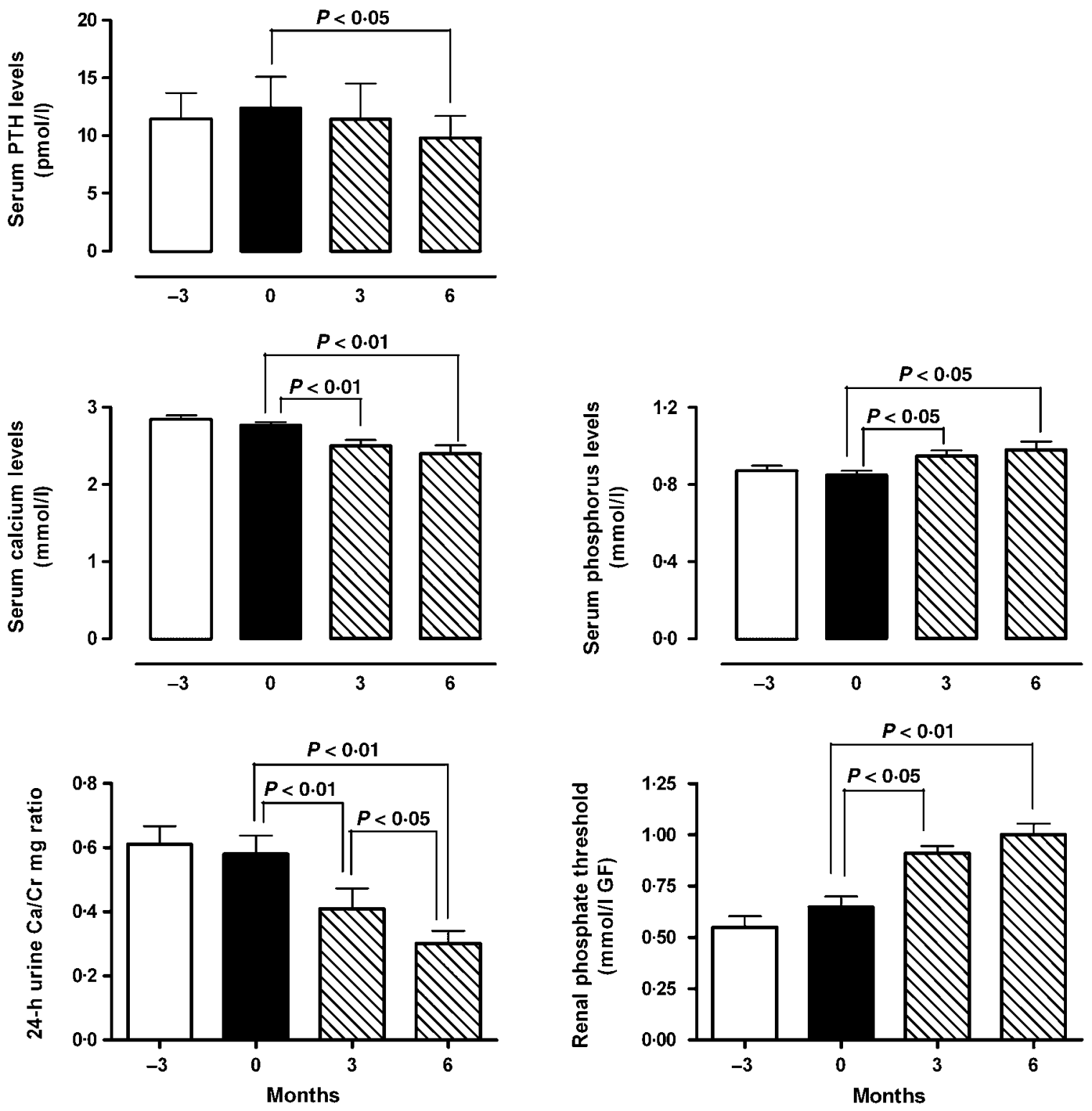

Fig. 2 Variations of serum concentrations of PTH, calcium and phosphorus, 24-h urine calcium : creatinine $(\mathrm{Ca} / \mathrm{Cr}) \mathrm{mg}$ ratio, renal phosphate threshold (expressed as mean \pm SEM) before (Time -3 and 0 month) and after (Time 3 and 6 months) therapy with octreotide LAR in eight patients with MEN1-dependent primary hyperparathyroidism.

Nowadays, there is no official indication for medical therapy alternative to surgery in PHP. Cinacalcet is a calcimimetic compound really promising for treating PHP: in preliminary studies it normalized hypercalcaemia and decreased PTH levels in several patients with sporadic PHP. ${ }^{4,5}$ However, these first observations did not include patients with MEN1 PHP. These patients are considered to be more difficult to manage, because of the involvement of the entire parathyroid tissue. Furthermore, the long-term efficacy and safety of cinacalcet has not been studied so far, and prospective randomized studies have to be performed in order to validate its usefulness in PHP.

If calcimimetic compounds are still experimental in MEN1 patients, SSA are effectively used to manage different types of NET in these patients. SSA are a helpful tool to treat both gastro- entero-pancreatic NET and pituitary adenomas. ${ }^{6-9}$ These tumours are known to express $\mathrm{SST}^{21-23}$ and are included in the last classification of NET. ${ }^{24}$ Parathyroid adenomas are also included in the classification of NET and, in patients with MEN1, they share a common pathogenic origin with gastro-entero-pancreatic NET and pituitary adenomas. $^{1-3,24}$

Somatostatin pathway has been poorly investigated in parathyroid tumours and perhaps SSA have been too early shelved as therapy for PHP after their initial negative or inconclusive results with shortacting octreotide. Neither a single acute administration nor a short-time therapy with subcutaneous octreotide $200 \mu \mathrm{g}$ daily induced beneficial changes in patients with PHP. ${ }^{10-12}$ Similarly, none of these studies reported significant changes of serum and urinary calcium concentrations. Only one case report showed improvement 

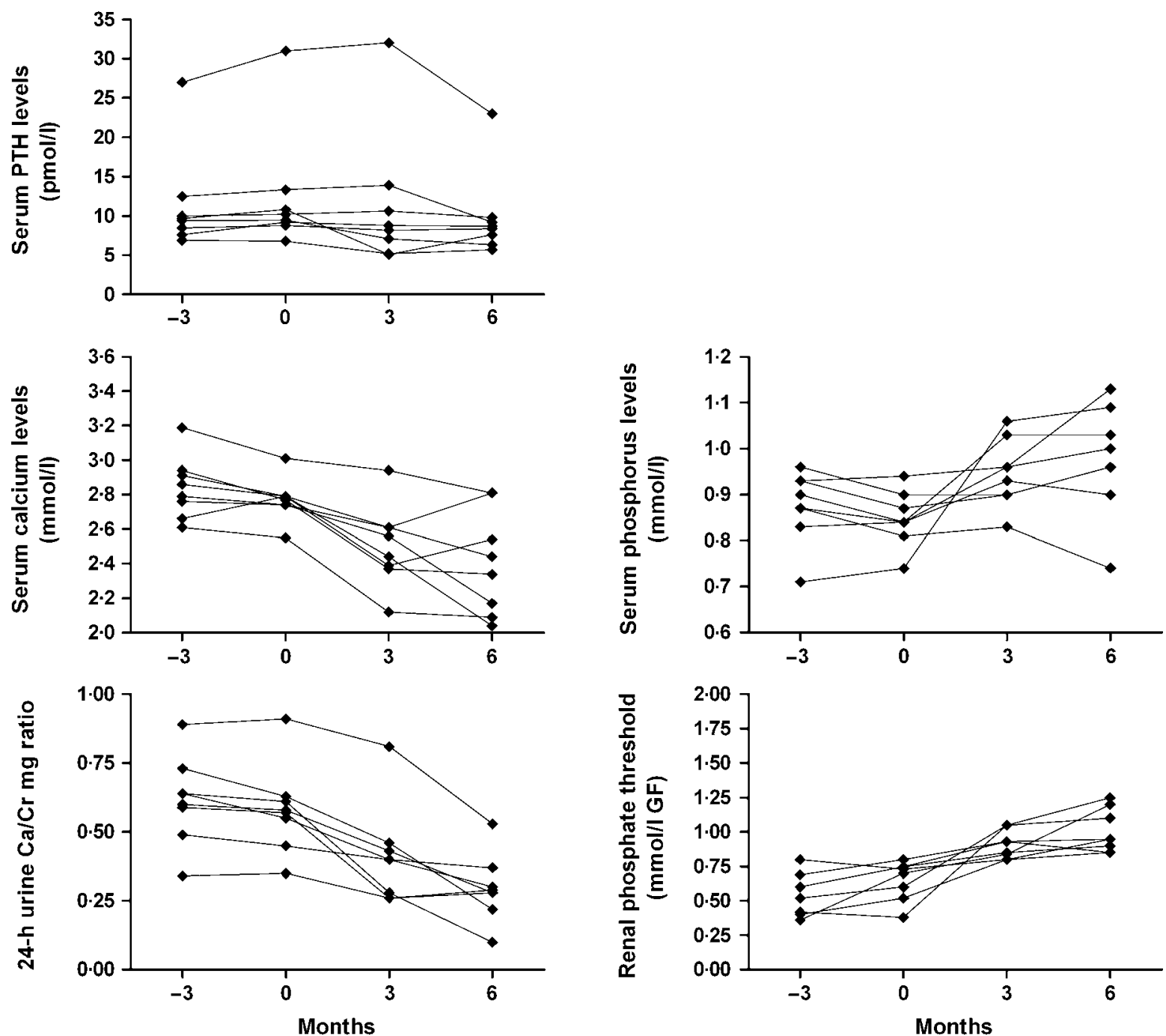

Fig. 3 Variations of serum concentrations of PTH, calcium and phosphorus, 24-h urine calcium : creatinine $(\mathrm{Ca} / \mathrm{Cr}) \mathrm{mg}$ ratio, renal phosphate threshold (expressed as individual data) before (Time -3 and 0 month) and after (Time 3 and 6 month) therapy with octreotide LAR in eight patients with MEN1-dependent primary hyperparathyroidism.

of hypercalcaemia ${ }^{10}$ and another study showed a significant decrease of hypercalciuria and a mild but not significant improvement of hypercalcaemia in 21 patients with PHP treated with octreotide $200 \mu \mathrm{g}$ daily for 6 days. ${ }^{11}$ In another patient with parathyroid carcinoma, improvement of hypercalciuria during 2 weeks of subcutaneous octreotide treatment was also reported. ${ }^{25}$ This effect was completely reversible and retrieved upon discontinuation or reintroduction, respectively, of octreotide. ${ }^{25}$ A few studies investigated the effects of long-term SSA therapy in MEN1 patients. Recently, one of two patients with MEN1-related PHP experienced decreased PTH levels after 6 months of subcutaneous octreotide treatment. ${ }^{13}$ This result was maintained after switching octreotide therapy from subcutaneous to depot formulation. No effect was observed on PTH levels in the second patient treated with OCT-LAR. ${ }^{13}$

In the current study, we investigated the effects of long-term OCTLAR treatment on PTH excess and related electrolytic disorders in a series of patients with MEN1 PHP. Our preliminary investigation highlighted some intriguing findings. The use of a long-acting slow-release SSA formulation for a longer period than in previous studies, gave more convincing results. ${ }^{10-12}$ Serum PTH significantly decreased in all of the patients and completely normalized in two of them after 6 months of OCT-LAR therapy. Results were even more evident on the biochemical abnormalities related to PTH excess. A clear-cut and stable decrease of serum calcium concentrations and urine calcium excretion was found after OCT-LAR therapy, resulting in normalized serum and urinary calcium levels in $75 \%$ and $62.5 \%$ of patients, respectively. At the same time, phosphate metabolism improved, as documented by a significant increase of serum phosphorus and renal threshold phosphate concentration. These findings probably reflect remarkable renal effects of the overall decrease in PTH secretion.

If the main biological effect of OCT-LAR on hyperparathyroidism in patients with MEN1 is a likely direct antisecretive activity on parathyroid adenomas, this effect may be mediated by SST activation. 
Immunohistochemistry for SST2A performed in three of the eight cases demonstrated this SST subtype to be expressed in parathyroid tumour cells. Furthermore, moderate-to-intense expression on the cell membrane surface suggests the functional activity of SST2 in parathyroid adenomas. In previous studies, autoradiography revealed specific SST binding of radio-labelled octreotide in peri-tumoral veins of parathyroid tumors ${ }^{12}$ but not in parathyroid tumour cells. ${ }^{26}$ Furthermore, a positive somatostatin immunostaining was reported in a case of parathyroid carcinoma which was partially responsive to SSA treatment ${ }^{25}$ as well as in human parathyroid adenomas. $^{27}$

In the current study, SST immunohistochemistry was not concordant with the in vivo analysis of SST expression. SST scintigraphy showed a low sensitivity in detecting parathyroid adenoma in MEN1 patients with PHP. The SST scintigraphy results were unrelated to SST immunostaining as well as to the biochemical response to OCT-LAR that occurred in either positive or negative patients at SST scintigraphy. The low sensitivity of SST scintigraphy together with its low ability in predicting the response to OCT-LAR may be explained by small parathyroid tumour size and low density of SST in tumour cells.

Besides the direct effects on PTH excess, exerted through specific SST on parathyroid tumour cells, OCT-LAR may also affect hyperparathyroidism and related electrolytic unbalances indirectly. The decrease in urinary calcium excretion after OCT-LAR may be in part PTH-independent and related to lowered intestinal calcium absorption $^{28}$ as a part of more general intestinal malabsorption caused by long-term therapy with SSA. ${ }^{29}$ Moreover, OCT-LAR may decrease intestinal absorption of calcium and consequently serum calcium concentrations and renal excretion of calcium through the inhibition of renal $1 \alpha$-hydroxylase activity resulting in decreased levels of 1,25-dihydroxyvitamin $\mathrm{D}$. This effect may be further enhanced by OCT-LAR-induced GH/IGF-I suppression, since GH is known to increase renal synthesis of 1,25-dihydroxyvitamin D. ${ }^{30}$ Although these indirect mechanisms may be partially responsible of changes in calcium/phosphorus homeostasis, the main activity of OCT-LAR in MEN1 patients with PHP is likely due to direct binding to SST expressed on parathyroid tumour cells.

In conclusion, this study identifies multiple endocrine neoplasia type 1-related primary hyperparathyroidism as a new potential target for therapy with long-acting somatostatin analogues. Serum PTH, calcium and phosphorus concentrations, urine calcium excretion and renal tubular reabsorption of phosphorus resulted all stably improved during a 6 month therapy with depot long acting octreotide. SST expression on parathyroid tumour cells suggests that depot long acting octreotide mainly improves calcium and phosphorus abnormalities through direct effects on PTH hypersecretion.

\section{References}

1 Brandi, M.L., Marx, S.J., Aurbach, G.D. \& Fitzpatrick, L.A. (1987) Familial multiple endocrine neoplasia type I: a new look at pathophysiology. Endocrine Reviews, 8, 391-405.

2 Marx, S., Spiegel, A.M., Skarulis, M.C., Doppman, J.L., Collins, F.S. \& Liotta, L.A. (1998) Multiple endocrine neoplasia type 1: clinical and genetic topics. Annals of Internal Medicine, 129, 484-494.
3 Benson, L., Ljunghall, S., Akerstrom, G. \& Oberg, K. (1987) Hyperparathyroidism presenting as the first lesion in multiple endocrine neoplasia type 1. American Journal of Medicine, 82, 731-737.

4 Shoback, D.M., Bilezikian, J.P., Turner, S.A., McCary, L.C., Guo, M.D. \& Peacock, M. (2003) The calcimimetic cinacalcet normalizes serum calcium in subjects with primary hyperparathyroidism. Journal of Clinical Endocrinology and Metabolism, 88, 5644-5649.

5 Peacock, M., Bilezikian, J.P., Klassen, P.S., Guo, M.D., Turner, S.A. \& Shoback, D. (2005) Cinacalcet hydrochloride maintains long-term normocalcemia in patients with primary hyperparathyroidism. Journal of Clinical Endocrinology and Metabolism, 90, 135-141.

6 Lamberts, S.W., de Herder, W.W., van Koetsveld, P.M., Koper, J.W., van der Lely, A.J., Visser-Wisselaar, H.A. \& Hofland, L.J. (1995) Somatostatin receptors: clinical implications for endocrinology and oncology. Ciba Foundation Symposium, 190, 222-236.

7 Oberg, K., Kvols, L., Caplin, M., Delle Fave, G., de Herder, W., Rindi, G., Ruszniewski, P., Woltering, E.A. \& Wiedenmann, B. (2004) Consensus report on the use of somatostatin analogs for the management of neuroendocrine tumors of the gastroenteropancreatic system. Annals of Oncology, 15, 966-973.

8 Burgess, J.R., Greenaway, T.M., Parameswaran, V. \& Shepherd, J.J. (1999) Octreotide improves biochemical, radiologic, and symptomatic indices of gastroenteropancreatic neoplasia in patients with multiple endocrine neoplasia type 1 (MEN-1). Implications for an integrated model of MEN-1 tumorigenesis. Cancer, 86, 2154-2159.

9 Beckers, A., Betea, D., Socin, H.V. \& Stevenaert, A. (2003) The treatment of sporadic versus MEN1-related pituitary adenomas. Journal of Internal Medicine, 253, 599-605.

10 Miller, D. \& Edmonds, M.W. (1991) Hypercalcemia due to hyperparathyroidism treated with a somatostatin analogue. Canadian Medical Association Journal, 145, 227-228.

11 Lucarotti, M.E., Hamilton, J.A. \& Farndon, J.R. (1994) Somatostatin and primary hyperparathyroidism. British Journal of Surgery, 81, 1141-1143.

12 Zielke, A., Hasse, C., Bruns, C., Sitter, H. \& Rothmund, M. (1997) Octreotide: effective treatment for hyperparathyroidism? A prospective, randomized, controlled clinical trial. Surgery, 121, 606-610.

13 Valkusz, Z., Gaspar, L., Julesz, J. \& Pavics, L. (2002) [Octreotide therapy in multiple endocrine neoplasia type-1]. Orvosi Hetilap, 143, $1078-1081$.

14 Freda, P.U., Katznelson, L., van der Lely, A.J., Reyes, C.M., Zhao, S. \& Rabinowitz, D. (2005) Long-acting somatostatin analog therapy of acromegaly: a meta-analysis. Journal of Clinical Endocrinology and Metabolism, 90, 4465-4473.

15 Walton, R.J. \& Bijvoet, O.L. (1975) Nomogram for derivation of renal threshold phosphate concentration. Lancet, 2, 309-310.

16 Krenning, E.P., Kwekkeboom, D.J., Oei, H.Y., de Jong, R.J., Dop, F.J., de Herder, W.W., Reubi, J.C. \& Lamberts, S.W. (1994) Somatostatin receptor scintigraphy in carcinoids, gastrinomas and Cushing's syndrome. Digestion, 55 (Suppl. 3), 54-59.

17 Volante, M., Brizzi, M.P., Faggiano, A., La Rosa, S., Rapa, I., Ferrero, A., Mansueto, G., Righi, L., Garancini, S., Capella, C., De Rosa, G., Dogliotti, L., Colao, A. \& Papotti, M. (2007) Somatostatin receptor type $2 \mathrm{~A}$ immunohistochemistry in neuroendocrine tumors: a proposal of scoring system correlated with somatostatin receptor scintigraphy. Modern Pathology, 20, 1172-1182.

18 Thompson, N.W. (1995) The surgical management of hyperparathyroidism and endocrine disease of the pancreas in the multiple endocrine neoplasia type 1 patient. Journal of Internal Medicine, 238, 269-280.

19 Dotzenrath, C., Cupisti, K., Goretzki, P.E., Yang, Q., Simon, D., 
Ohmann, C. \& Röher, H.D. (2001) Long-term biochemical results after operative treatment of primary hyperparathyroidism associated with multiple endocrine neoplasia types I and Ila: is a more or less extended operation essential? European Journal of Surgery, 167, $173-$ 178.

20 Elaraj, D.M., Skarulis, M.C., Libutti, S.K., Norton, J.A., Bartlett, D.L., Pingpank, J.F., Gibril, F., Weinstein, L.S., Jensen, R.T., Marx, S.J. \& Alexander, H.R. (2003) Results of initial operation for hyperparathyroidism in patients with multiple endocrine neoplasia type 1 . Surgery, 134, 858-864.

21 Rindi, G., Capella, C. \& Solcia, E. (2000) Introduction to a revised clinicopathological classification of neuroendocrine tumors of the gastroenteropancreatic tract. Quarterly Journal of Nuclear Medicine, 44, 13-21.

22 Patel, Y.C. (1999) Somatostatin and its receptor family. Frontiers in Neuroendocrinology, 20, 157-198.

23 Hofland, L.J. \& Lamberts, S.W. (2004) Somatostatin receptors in pituitary function, diagnosis and therapy. Frontiers in Hormone Research, 32, 235-252.

24 Solcia, E., Klöppel, G. \& Sobin, L.H. (2000) Histological typing of endocrine tumours. In World Health Organization International Histological Classification of Tumours. Springer-Verlag, Berlin Heidelberg New York.

25 Ybarra, J., Moises, J., Torregrosa, J.V., Madhun, Z.T. \& Schumacher,
O.P. (2001) [Effects of octreotide on serum and urine electrolytes in a patient with parathyroid carcinoma: clinical case]. Nefrologia, 21, 406-410.

26 Denzler, B. \& Reubi, J.C. (1999) Expression of somatostatin receptors in peritumoral veins of human tumors. Cancer, 85, 188-198.

27 Weber, C.J., O’Dorisio, T.M., Howe, B., D’Agati, V., Ward, L., Russell, J. \& Feind, C.R. (1991) Vasoactive intestinal polypeptide-, neurotensin-, substance P-, gastrin-releasing peptide-, calcitonin-, calcitonin gene related peptide-, and somatostatin-like immunoreactivities in human parathyroid glands. Surgery, 110, 1078-1085.

28 Cappelli, C., Gandossi, E., Agosti, B., Cerudelli, B., Cumetti, D., Castellano, M., Pirola, I., De Martino, E. \& Rosei, E.A. (2004) Long-term treatment of acromegaly with lanreotide: evidence of increased serum parathormone concentration. Endocrine Journal, 51, 517-520.

29 Chanson, P., Leselbaum, A., Blumberg, J. \& Schaison, G. (2000) Efficacy and tolerability of the long-acting somatostatin analog lanreotide in acromegaly. A 12-month multicenter study of 58 acromegalic patients. French Multicenter Study Group on Lanreotide in Acromegaly. Pituitary, 2, 269-276.

30 Wright, N.M., Papadea, N., Wentz, B., Hollis, B., Willi, S. \& Bell, N.H. (1997) Increased serum 1,25-dihydroxyvitamin D after growth hormone administration is not parathyroid hormone-mediated. Calcified Tissue International, 61, 101-103. 